\title{
A PET Brain Reporter Gene System Based on Type 2 Cannabinoid Receptors
}

\author{
Caroline Vandeputte ${ }^{* 1-3}$, Nele Evens ${ }^{* 4}$, Jaan Toelen $^{5}$, Christophe M. Deroose ${ }^{1,2}$, Barbara Bosier ${ }^{6}$, Abdelilah Ibrahimi ${ }^{2,5}$, \\ Anke Van der Perren ${ }^{3}$, Rik Gijsbers ${ }^{5}$, Peter Janssen ${ }^{7}$, Didier M. Lambert ${ }^{6}$, Alfons Verbruggen ${ }^{2,4}$, Zeger Debyser ${ }^{2,5}$, \\ Guy Bormans ${ }^{2,4}$, Veerle Baekelandt ${ }^{2,3}$, and Koen Van Laere ${ }^{1,2}$ \\ ${ }^{1}$ Division of Nuclear Medicine, University Hospital and K.U. Leuven, Leuven, Belgium; ${ }^{2}$ Molecular Small Animal Imaging Center, \\ MoSAIC, K.U. Leuven, Leuven, Belgium; ${ }^{3}$ Laboratory for Neurobiology and Gene Therapy, Molecular Medicine, K.U. Leuven, \\ Leuven, Belgium; ${ }^{4}$ Laboratory for Radiopharmacy, K.U. Leuven, Leuven, Belgium; ${ }^{5}$ Laboratory for Molecular Virology and Gene \\ Therapy, Molecular Medicine, K.U. Leuven, Leuven, Belgium; ${ }^{6}$ Louvain Drug Research Institute, Medicinal Chemistry Group, U.C. \\ Louvain, Woluwe-Saint-Lambert, Belgium; and ${ }^{7}$ Laboratory for Neuro- and Psychophysiology, K.U. Leuven, Leuven, Belgium
}

PET of gene expression in the brain may greatly facilitate neuroscience research and potential clinical implementation of gene or cell therapy of central nervous system diseases. To date, no adequate PET reporter system is available for the central nervous system because available tracers either do not cross the intact blood-brain barrier or have high background signals. Here we report the first, to our knowledge, PET reporter system for imaging gene expression in the intact brain. Methods: We selected the human type 2 cannabinoid receptor $\left(\mathrm{hCB}_{2}\right)$ as a reporter because of its low basal expression in the brain. An inactive mutant (D80N) was chosen so as not to interfere with signal transduction. As a reporter probe we used the ${ }^{11} \mathrm{C}$-labeled $\mathrm{CB}_{2}$ ligand, ${ }^{11} \mathrm{C}-\mathrm{GW} 405833$, which readily crosses the blood-brain barrier. Dual-modality imaging lentiviral and adeno-associated viral vectors encoding both $\mathrm{hCB}_{2}(\mathrm{D} 80 \mathrm{~N})$ and firefly luciferase or enhanced green fluorescent protein were engineered and validated in cell culture. Next, $\mathrm{hCB}_{2}(\mathrm{D} 80 \mathrm{~N})$ was locoregionally overexpressed in rat striatum by stereotactic injection of lentiviral and adeno-associated viral vectors. Results: Kinetic PET revealed specific and reversible $\mathrm{CB}_{2}$ binding of ${ }^{11} \mathrm{C}-\mathrm{GW} 405833$ in the transduced rat striatum. $\mathrm{hCB}_{2}$ and firefly luciferase expression was followed until $9 \mathrm{mo}$ and showed similar kinetics. Both $\mathrm{hCB}_{2}$ expression and enhanced green fluorescent protein expression were confirmed by immunohistochemistry. Conclusion: Dual-modality imaging viral vectors encoding $\mathrm{hCB}_{2}(\mathrm{D} 80 \mathrm{~N})$ were engineered, and the reporter system was validated in different animal species. The results support the potential future clinical use of $\mathrm{CB}_{2}$ as a PET reporter in the intact brain.

Key Words: $\mathrm{CB}_{2}$ receptor; positron emission tomography; ${ }^{11} \mathrm{C}-$ GW405833; reporter gene; brain

J Nucl Med 2011; 52:1102-1109

DOI: 10.2967/jnumed.110.084426

\footnotetext{
Received Oct. 25, 2010; revision accepted Mar. 16, 2011.

For correspondence or reprints contact: Koen Van Laere, Division of Nuclear Medicine, K.U. Leuven, Herestraat 49, Bus 7001, 3000 Leuven, Belgium.

E-mail: Koen.vanlaere@uz.kuleuven.ac.be

${ }^{*}$ Contributed equally to this work.

COPYRIGHT @ 2011 by the Society of Nuclear Medicine, Inc.
}

$\mathbf{G}$ ene therapy is an investigational technique for various neurologic diseases (1). Besides locoregional delivery of the therapeutic agent, the main challenges are assessment of location, magnitude, and duration of gene expression in the treated subjects. To meet this requirement, expression of the therapeutic gene can be linked with that of a reporter gene (2). Several reporter systems for molecular imaging have been developed (3), such as enhanced green fluorescent protein (eGFP, fluorescence detection) (4), firefly luciferase (fLuc, bioluminescence imaging) (5), and herpes simplex virus type 1 thymidine kinase (HSV1-tk), the expression of which can be visualized with PET or SPECT after injection of a radiolabeled HSV1-tk substrate (6).

PET offers sensitive and quantitative 3-dimensional imaging with the potential of translation to clinical applications. Ideally, the reporter gene should be nonimmunogenic and metabolically inactive but should not be endogenously expressed. The reporter tracer should be able to cross the blood-brain barrier (BBB), should have high affinity and selectivity for the protein encoded by the reporter gene, and should have fast washout kinetics (7). Despite the promising results in peripheral tissues, molecular imaging of reporter genes in the brain is hampered by penetration issues (8) or confounding signals due to high endogenous levels (9).

Since the discovery of cannabinoid receptors, the endocannabinoid system has shown promise as a target for the treatment of neurodegenerative diseases, cancer, obesity, inflammatory bowel disease, and pain (10). The endocannabinoid system is distributed throughout the body and involves at least 2 types of G-protein-coupled receptors, namely type 1 cannabinoid receptor $\left(\mathrm{CB}_{1}\right)$ and type 2 cannabinoid receptor $\left(\mathrm{CB}_{2}\right)(10)$. $\mathrm{CB}_{1}$ is one of the most abundantly expressed receptors of the central nervous system, whereas $\mathrm{CB}_{2}$ is mainly found in spleen and cells of the immune system (11). In physiologic conditions, $\mathrm{CB}_{2}$ expression in the brain is low and present only in the cerebellum and pons, but expression can be upregulated in 
inflammatory conditions by activated microglia (12). The highly conserved aspartic acid D80 in the second transmembrane domain of $\mathrm{CB}_{2}$ is functionally important for G-protein coupling. A mutant form of human $\mathrm{CB}_{2}$ with a D80N substitution displays wild-type ligand recognition and binding but is deficient for signal transduction (13).

Currently, several $\mathrm{CB}_{2}$ PET tracers for human imaging are under development but none has been used in humans yet $(14,15)$. GW405833 $(\mathrm{L}-768,242)$ is a $\mathrm{CB}_{2}$-selective partial agonist (16), known to cross the BBB (17). In this study, we engineered a novel PET reporter system based on either a lentiviral or an adeno-associated viral (AAV) vector expressing $\mathrm{hCB}_{2}(\mathrm{D} 80 \mathrm{~N})$ as a reporter gene (Fig. 1). We evaluated ${ }^{11} \mathrm{C}-\mathrm{GW} 405833$ as a PET tracer for $\mathrm{CB}_{2}$ in several species and validated the new $\mathrm{hCB}_{2}(\mathrm{D} 80 \mathrm{~N})$-based reporter system both in vitro and in vivo.

\section{MATERIALS AND METHODS}

The methodology used for the chemical synthesis and radiosynthesis of the radioligand; the measurement of the distribution coefficient; the biodistribution studies; the viral vector construction and production; cell culture and transduction; Western blot analysis; stereotactic injections; bioluminescence imaging; and immunofluorescence and immunohistochemistry have been described in the supplemental data (available online only at http:// jnm.snmjournals.org).

\section{Biodistribution Studies in Mouse and Rat}

Studies were performed in accordance with the current institutional regulations for use and care of laboratory animals provided by the University of Leuven (P03103, P067/2009) and approved by the local ethical committee for animal experiments of K.U. Leuven.

\section{Plasma and Brain Metabolites in Mouse}

Radiometabolites were quantified in the plasma and brains of male NMRI mice according to previously described methods (18).
Plasma was analyzed on an Oasis hydrophilic-lipophilic balanced column $(4.6 \times 20 \mathrm{~mm}$; Waters $)$ connected to an analytic XTerra RP18 column $(5 \mu \mathrm{m}, 4.6 \times 250 \mathrm{~mm}$; Waters) eluted using $0.05 \mathrm{M}$ ammonium acetate, $\mathrm{pH}$ 6.9/acetonitrile (30/70 v/v, $1 \mathrm{~mL} / \mathrm{min})$. Brain samples were analyzed on a high-performance liquid chromatography system comprising an XTerra RP18 column $(5 \mu \mathrm{m}$, $4.6 \times 250 \mathrm{~mm}$; Waters) and ammonium acetate buffer, $0.05 \mathrm{M}, \mathrm{pH}$ 6.9/acetonitrile 40/60 (v/v) as a mobile phase (1 mL/min).

\section{PET Study in Rhesus Monkey}

A juvenile male rhesus monkey (Macaca mulatta, $5.0 \mathrm{~kg}$ ) was sedated with ketamine (Ketalar; Pfizer) and medetomidine hydrochloride (Domitor; Pfizer). The monkey was injected with 122 $\mathrm{MBq}$ of ${ }^{11} \mathrm{C}-\mathrm{GW} 405855$ via the vena saphena. PET was performed using a Focus 220 tomograph (Siemens/Concorde Microsystems), which has a nominal transaxial resolution of $1.35 \mathrm{~mm}$ in full width at half maximum. Dynamic small-animal PET images were acquired for $90 \mathrm{~min}$ and were reconstructed using filtered backprojection with a RAMP filter. Data were analyzed using PMOD software (version 2.7; PMOD Technologies); volumes of interest were defined on the summed images and time-activity curves were drawn. Anatomic MR images were acquired on a Siemens 3-T scanner at a resolution of $0.6 \mathrm{~mm}$ isotropic.

\section{Competition Binding Assay and ${ }^{35}$ S-GTP $\gamma$ S Assay}

The competition binding assay and ${ }^{35} \mathrm{~S}-\mathrm{GTP} \gamma \mathrm{S}$ assay were done according to previously described methods (19).

\section{Immunocytochemistry}

After fixation, SHSY5Y cells were incubated with a blocking buffer containing $10 \%$ horse serum for $20 \mathrm{~min}$, followed by a $90-$ min incubation with primary antibody against $\mathrm{CB}_{2}$ (rabbit, 1:400; Cayman Chemical). After being washed 3 times with phosphatebuffered saline for $5 \mathrm{~min}$, the plates were incubated for $1 \mathrm{~h}$ with secondary antibody (donkey-antirabbit, CY3 543 nm, 1:400; Jackson ImmunoResearch Laboratories, Inc.). Thereafter, the glass plates were mounted on a cover glass, and the expression of $\mathrm{hCB}_{2}(\mathrm{D} 80 \mathrm{~N})$ was analyzed by fluorescence microscopy (Leica DMR).

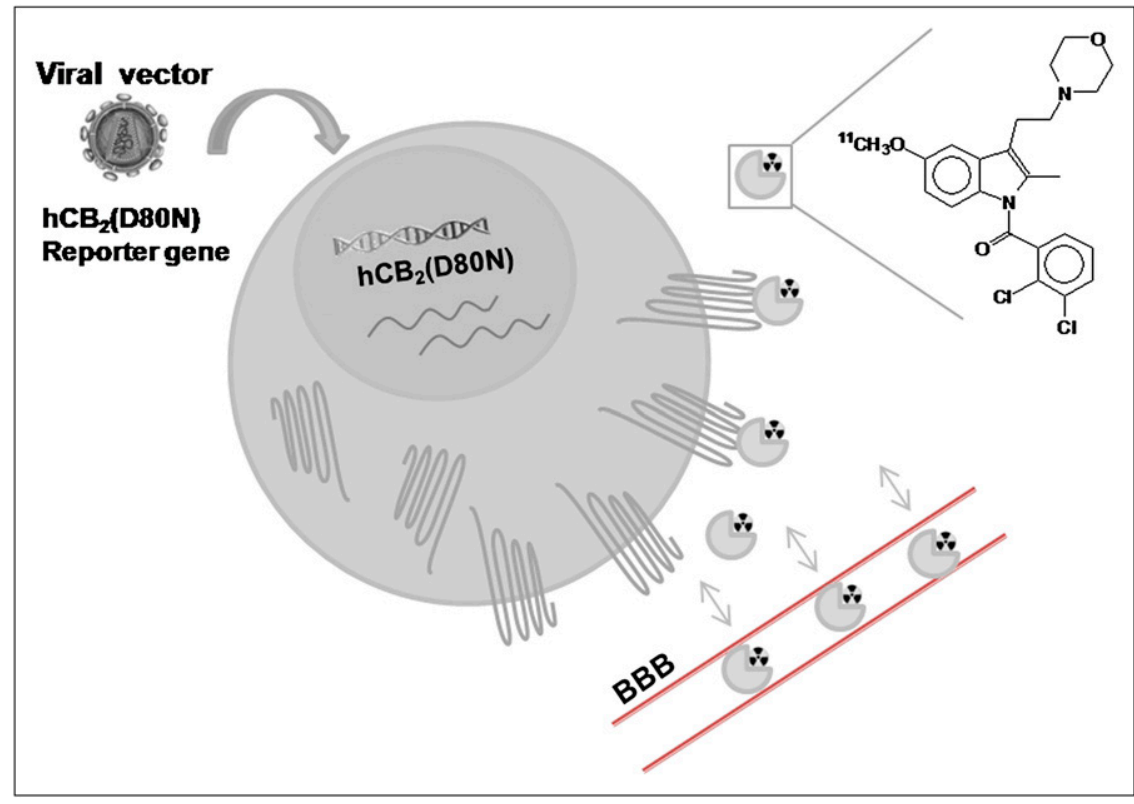

FIGURE 1. Schematic representation of $\mathrm{CB}_{2}$ reporter gene imaging with reporter probe ${ }^{11} \mathrm{C}-\mathrm{GW} 405833$. Cells are transduced with viral vector encoding $\mathrm{hCB}_{2}(\mathrm{D} 80 \mathrm{~N})$ as reporter gene. $\mathrm{hCB}_{2}(\mathrm{D} 80 \mathrm{~N})$ is transcribed to $\mathrm{hCB}_{2}(\mathrm{D} 80 \mathrm{~N})$ messenger RNA and then translated to $\mathrm{hCB}_{2}(\mathrm{D} 80 \mathrm{~N})$. After administration of $\mathrm{CB}_{2}$-specific radioligand, ${ }^{11} \mathrm{C}$ GW405833, which crosses BBB, the probe binds to $\mathrm{hCB}_{2}(\mathrm{D} 80 \mathrm{~N})$. Magnitude of accumulation of ${ }^{11} \mathrm{C}$-GW405833 reflects level of $\mathrm{hCB}_{2}(\mathrm{D} 80 \mathrm{~N})$ gene expression. 


\section{PET of $\mathrm{hCB}_{\mathbf{2}}(\mathrm{D} 80 \mathrm{~N})$ Expression}

Images of $\mathrm{CB}_{2}$ binding in the brain were obtained using the radioligand ${ }^{11} \mathrm{C}-\mathrm{GW} 405833$. Before PET, rats were anesthetized using $3 \%$ isoflurane in $2.0 \mathrm{~L}$ of oxygen per minute. The tail vein was catheterized to enable the infusion of ${ }^{11} \mathrm{C}-\mathrm{GW} 405833 .{ }^{11} \mathrm{C}$ GW405833 was diluted with saline to obtain a solution with a maximum of $10 \%$ ethanol and injected in a total volume of approximately $500 \mu \mathrm{L}$. A dynamic acquisition (60 min) was started immediately after intravenous injection of approximately $37 \mathrm{MBq}$ of the tracer. For the $1 \mathrm{wk}$ scan of the rats injected with lentiviral-hCB $\mathrm{h}_{2}(\mathrm{D} 80 \mathrm{~N})$, a 20 -min scan was obtained $10 \mathrm{~min}$ after injection of the tracer.

Specific binding to $\mathrm{CB}_{2}$ was confirmed by a chase study $41 \mathrm{~d}$ after stereotactic injection of $5 \mu \mathrm{L}$ of AAV-eGFP-T2A-hCB 2 $(\mathrm{D} 80 \mathrm{~N})(5 \mathrm{E}+08$ genome copies $[\mathrm{GC}])$ in the right striatum and $5 \mu \mathrm{L}$ of AAV-eGFP-T2A-fLuc $(5 \mathrm{E}+09 \mathrm{GC})$ in the left striatum of a rat. A dynamic acquisition (90 min) was started immediately after intravenous injection of approximately $37 \mathrm{MBq}$ of ${ }^{11} \mathrm{C}-\mathrm{GW} 405833$. Twenty minutes after tracer injection, the animal was treated intravenously with a solution of nonradioactive GW405833 (5 mg/kg, solution in $10 \%$ dimethyl sulfoxide and $2 \%$ polysorbate80 in water for injection), thereby confirming specific binding of ${ }^{11} \mathrm{C}-\mathrm{GW} 405833$.

Scans were reconstructed via filtered backprojection. Smallanimal PET images were spatially normalized to a stereotactic space and analyzed using a predefined volume-of-interest approach. The procedure of spatial normalization and its validation have been described previously (20). For the analysis of lentiviral$\mathrm{hCB}_{2}(\mathrm{D} 80 \mathrm{~N})$, volumes of interest were defined manually and the binding potential was derived from a Logan graphical method using the cerebellum as a reference region.

\section{RESULTS}

\section{Radiosynthesis and In Vitro and In Vivo Validation of GW405833 and ${ }^{11} \mathbf{C}-$ GW405833}

Radiosynthesis. Synthesis of GW405833 was based on literature methods (17). A precursor for ${ }^{11} \mathrm{C}$ labeling (1) was obtained in moderate yield $(62 \%)$ by demethylation using $\mathrm{BBr}_{3}$. Radiosynthesis of ${ }^{11} \mathrm{C}-\mathrm{GW} 405833$ was performed by bubbling ${ }^{11} \mathrm{C}$-methyl iodide or ${ }^{11} \mathrm{C}$-methyl triflate through a solution of $\underline{\mathbf{1}}$ in $\mathrm{N}, \mathrm{N}$-dimethylformamide in alkaline conditions. Similar alkylation yields were obtained whether ${ }^{11} \mathrm{C}-\mathrm{CH}_{3} \mathrm{I}$ or ${ }^{11} \mathrm{C}$-methyl triflate was used $(33 \% \pm$ $17 \%[n=10]$ or $29 \% \pm 7 \%[n=28]$, respectively) (Supplemental Fig. 1).

Distribution Coefficient, Polar Surface Area. The lipophilicity of ${ }^{11} \mathrm{C}-\mathrm{GW} 405833$ was determined by partitioning between 1-octanol and $0.025 \mathrm{M}$ phosphate buffer, $\mathrm{pH}$ 7.4, and a theoretic polar surface area (tPSA) was calculated (http://www.daylight.com/meetings/emug00/Ertl/tpsa. html). The $\log \mathrm{D}$ value of ${ }^{11} \mathrm{C}-\mathrm{GW} 405833$ was 2.5 , and the tPSA was $4.37 \mathrm{~nm}^{2}\left(43.7 \AA^{2}\right)$.

Biodistribution Studies in Mouse and Rat. The biodistribution of ${ }^{11} \mathrm{C}-\mathrm{GW} 405833$ was similar in rats and mice (Table 1 and Supplemental Table 1). The compound is cleared by the hepatobiliary system, but intestinal excretion is faster in mice than in rats $(49.6 \%$ and $6 \%$ of injected dose in intestines at $60 \mathrm{~min}$ after injection in mice and rats, respectively). Brain uptake was high (mean standard uptake value $\left[\mathrm{SUV}_{\text {mean }}\right], 1.4$ and 1.8 at $2 \mathrm{~min}$ after injection for mice and rats, respectively). Several well-perfused organs showed high initial tracer uptake. Initial uptake in kidneys was high, but no excretion in urine was observed. Except for the liver, which has a role in excretion, no major organ retained the tracer. Blood values remained persistently high.

Plasma and Brain Radiometabolite Analysis in Mouse. Plasma analysis after intravenous injection showed fast metabolism of the tracer, with only $15 \%$ of intact tracer left at $30 \mathrm{~min}$ after injection (Supplemental Fig. 2). Only more polar metabolites relative to ${ }^{11} \mathrm{C}-\mathrm{GW} 405833$ were observed. In the brain, more than $90 \%$ of the activity found at $10 \mathrm{~min}$ after injection was due to the presence of intact tracer.

PET in Rhesus Monkey. A relatively high initial brain uptake of ${ }^{11} \mathrm{C}-\mathrm{GW} 405833$ was found in a monkey small-

TABLE 1

Biodistribution of ${ }^{11} \mathrm{C}-\mathrm{GW} 405833$ in Wistar Rats

\begin{tabular}{|c|c|c|c|c|c|c|}
\hline \multirow[b]{2}{*}{ Organ } & \multicolumn{3}{|c|}{ Percentage injected dose $\pm \mathrm{SD}$} & \multicolumn{3}{|c|}{ Standardized uptake value \pm SD } \\
\hline & $2 \min$ & $30 \mathrm{~min}$ & $60 \mathrm{~min}$ & $2 \min$ & $30 \mathrm{~min}$ & $60 \mathrm{~min}$ \\
\hline Kidneys & $6.1 \pm 0.4$ & $2.2 \pm 1.2$ & $3.1 \pm 1.1$ & $7.6 \pm 1.2$ & $2.6 \pm 1.6$ & $3.4 \pm 1.3$ \\
\hline Urine & $0.0 \pm 0.0$ & $0.0 \pm 0.0$ & $0.2 \pm 0.1$ & - & - & - \\
\hline Liver & $32.3 \pm 3.3$ & $63.9 \pm 1.2$ & $61.8 \pm 4.4$ & $10.9 \pm 1.1$ & $15.2 \pm 0.4$ & $14.9 \pm 1.6$ \\
\hline Spleen & $1.6 \pm 0.2$ & $0.3 \pm 0.0$ & $0.1 \pm 0.0$ & $6.7 \pm 1.5$ & $1.1 \pm 0.1$ & $0.6 \pm 0.0$ \\
\hline Pancreas & $1.2 \pm 0.1$ & $0.3 \pm 0.0$ & $0.2 \pm 0.1$ & $4.7 \pm 0.7$ & $0.9 \pm 0.1$ & $0.8 \pm 0.2$ \\
\hline Lungs & $10.5 \pm 5.0$ & $0.8 \pm 0.3$ & $0.6 \pm 0.0$ & $17.8 \pm 7.1$ & $1.3 \pm 0.3$ & $1.1 \pm 0.1$ \\
\hline Heart & $1.9 \pm 0.1$ & $0.1 \pm 0.0$ & $0.1 \pm 0.0$ & $6.3 \pm 0.9$ & $0.4 \pm 0.0$ & $0.4 \pm 0.0$ \\
\hline Intestines & $10.3 \pm 0.6$ & $4.3 \pm 0.2$ & $5.7 \pm 0.9$ & - & - & - \\
\hline Stomach & $2.1 \pm 0.6$ & $2.9 \pm 0.1$ & $4.7 \pm 2.6$ & - & - & - \\
\hline Blood & $4.5 \pm 0.9$ & $0.9 \pm 0.1$ & $1.1 \pm 0.2$ & $0.6 \pm 0.1$ & $0.1 \pm 0.0$ & $0.2 \pm 0.0$ \\
\hline Brain & $1.4 \pm 0.2$ & $0.3 \pm 0.0$ & $0.2 \pm 0.0$ & $1.8 \pm 0.3$ & $0.4 \pm 0.0$ & $0.2 \pm 0.0$ \\
\hline
\end{tabular}

Percentage injected dose was calculated as cpm in organ divided by total cpm recovered. Standardized uptake values were calculated as (radioactivity in cpm in organ/weight of organ in grams)/(total counts recovered/body weight in grams). Data are expressed as mean \pm SD for 3 independent experiments. 
animal PET study ( $\mathrm{SUV}_{\text {mean }}, 2.0$ at 2 min after injection in frontal cortex) (Supplemental Fig. 3). Uptake in brain regions other than the frontal cortex was slightly lower $\left(\mathrm{SUV}_{\text {mean }}, 1.5\right.$ at $2 \mathrm{~min}$ after injection) in the thalamus, pons, and cerebellum and about half as much ( $\mathrm{SUV}_{\text {mean }}$, 1.0 at 2 min after injection) in the white matter. Washout from white matter was slower than from other brain regions.

In Vitro Studies. Nonradioactive GW405833 was evaluated for its $\mathrm{CB}_{1}$ and $\mathrm{CB}_{2}$ affinity in a competition binding assay using human $\mathrm{CB}_{1}\left(\mathrm{hCB}_{1}\right)$ or $\mathrm{hCB}_{2}$ expressing Chinese hamster ovary cells. The affinity $\left(\mathrm{K}_{\mathrm{i}}\right.$ value) of GW405833 was $6 \mu \mathrm{M}$ and $35 \mathrm{nM}$ for $\mathrm{hCB}_{1}$ and $\mathrm{hCB}_{2}$, respectively. A ${ }^{35} \mathrm{~S}-\mathrm{GTP} \gamma \mathrm{S}$ assay was performed for evaluation of the compounds' potency and efficacy in signal transduction. GW405833 behaved as an inverse agonist (half maximal effective concentration $\left[\mathrm{EC}_{50}\right], 23 \mathrm{nM}$ ) (Supplemental Fig. 4).

\section{Lentiviral Vector-Mediated Overexpression of $\mathbf{h C B}_{\mathbf{2}}(\mathrm{D} 80 \mathrm{~N})$ in Cell Culture}

After validation of the $\mathrm{CB}_{2}$ PET tracer ${ }^{11} \mathrm{C}-\mathrm{GW} 405833$ for applications in the intact brain, we decided to design a new PET reporter system for monitoring gene expression in the central nervous system (Fig. 1). Apart from requiring a suitable tracer, a PET reporter system requires a reporter and a gene transfer vehicle. To stably overexpress $\mathrm{hCB}_{2}$ (D80N) in nondividing neuronal cells, lentiviral or AAV vectors could be used.

First, a monocistronic lentiviral construct encoding $\mathrm{hCB}_{2}(\mathrm{D} 80 \mathrm{~N})$ under control of the ubiquitous human cytomegalovirus immediate-early (hCMVie) promoter was constructed (lentiviral-hCB $\mathrm{CB}_{2}(\mathrm{D} 80 \mathrm{~N})$ ). In parallel, bicistronic lentiviral constructs expressing $\mathrm{hCB}_{2}(\mathrm{D} 80 \mathrm{~N})$ with either eGFP (lentiviral-hCB $\left.{ }_{2}(\mathrm{D} 80 \mathrm{~N})-I R E S-e G F P\right)$ or the hygromycin resistance protein, hygromycin $\mathrm{B}$ phosphotransferase (lentiviral-hCB $\left.\mathrm{B}_{2}(\mathrm{D} 80 \mathrm{~N})-\mathrm{IRES}-\mathrm{Hygro}\right)$, linked in both cases with an IRES (internal ribosomal entry site) element were engineered (Fig. 2).

Human embryonic kidney-293T cells were transduced with serial dilutions of lentiviral-hCB $\mathrm{CB}_{2}(\mathrm{D} 80 \mathrm{~N})$, and expression was verified by Western blotting (Supplemental Fig. 5A). We observed 3 distinct bands of 41, 45, and greater than $200 \mathrm{kDa}$, corresponding to the nonglycosylated $\mathrm{CB}_{2}$, glycosylated $\mathrm{CB}_{2}$, and $\mathrm{CB}_{2}$ aggregates, respectively. These aggregates are a result of heating before sodium dodecyl sulfate polyacrylamide gel electrophoresis, as detailed in a previous study (21). In the absence of heating, protein aggregation was significantly reduced (Supplemental Fig. $5 B$ ). $\mathrm{CB}_{2}$ expression correlated with vector dilution (Supplemental Fig. 5A).

The expression of $\mathrm{hCB}_{2}(\mathrm{D} 80 \mathrm{~N})$ was also evaluated by immunocytochemistry in SHSY5Y (human dopaminergic neuroblastoma) cells, to allow subcellular $\mathrm{hCB}_{2}(\mathrm{D} 80 \mathrm{~N})$ localization (Supplemental Fig. 5). $\mathrm{CB}_{2}$ expression was detected in the cells that were transduced with either lentiviral$\mathrm{hCB}_{2}(\mathrm{D} 80 \mathrm{~N})$ (Supplemental Figs. 5E and 5F), lentiviral$\mathrm{hCB}_{2}$ (D80N)-IRES-eGFP (Supplemental Figs. 5G and 5H), or lentiviral-hCB $\mathrm{CB}_{2}(\mathrm{D} 80 \mathrm{~N})-$ IRES-Hygro (Supplemental Figs. 5I and 5J). No $\mathrm{CB}_{2}$ expression was seen in control SHSY5Y cells that were transduced with lentiviral-IRES-eGFP (Supplemental Fig. 5C and 5D). Supplemental Figure 6 shows expression of both $\mathrm{CB}_{2}$ and eGFP in a SHSY5Y cell cotransfected with both $\mathrm{hCB}_{2}(\mathrm{D} 80 \mathrm{~N})$ and eGFP.

\section{In Vivo Validation of $\mathbf{h C B}_{\mathbf{2}}(\mathrm{D} 80 \mathrm{~N})$ Reporter System}

To validate the $\mathrm{hCB}_{2}(\mathrm{D} 80 \mathrm{~N})$ reporter system in vivo, 7 Wistar rats were stereotactically injected with $5 \mu \mathrm{L}$ of lentiviral-hCB ${ }_{2}(\mathrm{D} 80 \mathrm{~N})(1.56 \mathrm{E}+06 \mathrm{pg} \mathrm{p} 24 / \mathrm{mL})$ in the right striatum (RS), and $5 \mu \mathrm{L}$ of lentiviral-eGFP (similar concentration) was injected in the left striatum (LS). Animals were scanned after ${ }^{11} \mathrm{C}-\mathrm{GW} 405833$ injection 1 wk later. One of the animals showed an increased tracer uptake in the RS, compared with the contralateral hemisphere $(51 \pm$

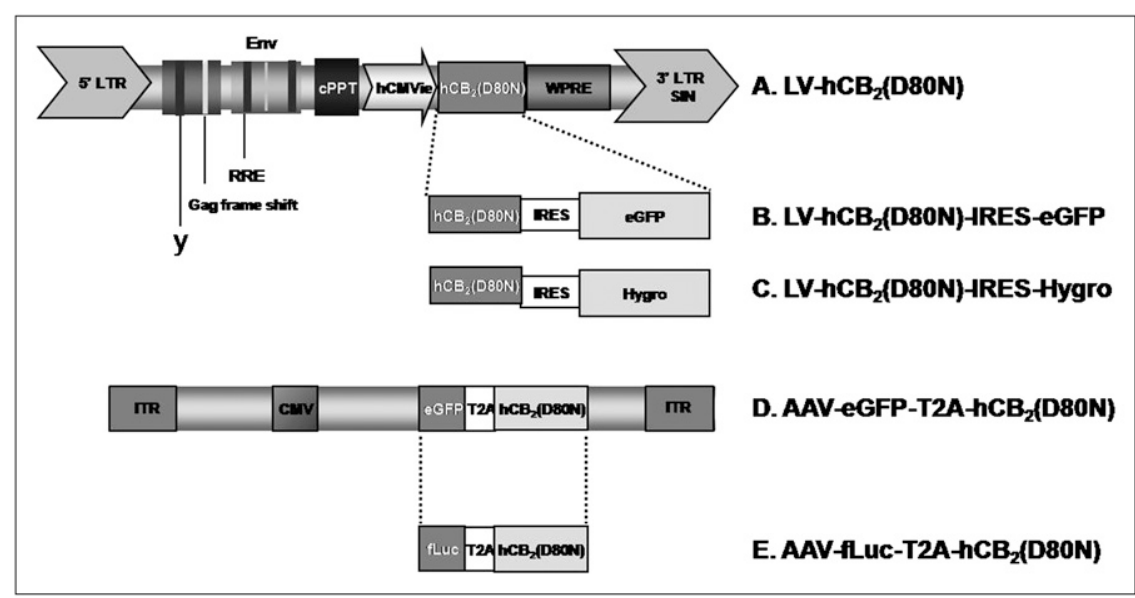

FIGURE 2. Viral vector-mediated overexpression of $\mathrm{hCB}_{2}(\mathrm{D} 80 \mathrm{~N})$ in cell culture. In lentiviral constructs, reporter genes are driven by hCMVie promoter and followed by woodchuck hepatitis posttranscriptional element (WPRE). Promoter is preceded by central polypurine tract (cPPT), and lentiviral cassette is flanked by $5^{\prime}$ long terminal repeat (LTR) and $3^{\prime}$ self-inactivating (SIN) LTR. (A-C) Monocistronic construct expressing $\mathrm{hCB}_{2}(\mathrm{D} 80 \mathrm{~N})(\mathrm{A}), \mathrm{hCB}_{2}(\mathrm{D} 80 \mathrm{~N})$ linked to eGFP by IRES sequence (B), or $h \mathrm{CB}_{2}(\mathrm{D} 80 \mathrm{~N})$ linked to hygromycin $B$ phosphotransferase (C). AAV 2/7 constructs are driven by hCMVie promoter, and AAV cassette is flanked by inverted terminal repeats (ITR). (D and E) Bicistronic construct encoding eGFP or fLuc and $\mathrm{hCB}_{2}(\mathrm{D} 80 \mathrm{~N})$, linked by self-cleaving $\mathrm{T} 2 \mathrm{~A} 2 \mathrm{~A}$ sequence. $\mathrm{CMV}=$ cytomegalovirus. 
$2 \mathrm{kBq} / \mathrm{cm}^{3}$ in RS, $>42 \pm 1 \mathrm{kBq} / \mathrm{cm}^{3}$ in LS) (Supplemental Figs. 7A-7C), which was confirmed by a dynamic scan $3 \mathrm{~d}$ later (data not shown) and the detection of $\mathrm{hCB}_{2}(\mathrm{D} 80 \mathrm{~N})$ overexpression in the RS by immunohistochemical analysis (Supplemental Fig. 7D). The other animals showed no differences in tracer uptake between the 2 hemispheres on small-animal PET images. Immunohistochemistry revealed overexpression of eGFP in the LS but low expression of $\mathrm{hCB}_{2}(\mathrm{D} 80 \mathrm{~N})$ in the RS. Although the lentiviral$\mathrm{hCB}_{2}(\mathrm{D} 80 \mathrm{~N})$ constructs were adequate for in vitro validation of cell labeling, they failed to induce sufficient $\mathrm{hCB}_{2}(\mathrm{D} 80 \mathrm{~N})$ expression to be detected by PET in all animals. Because AAV vectors can induce higher transgene expression levels in the brain mainly because of their higher titers, we designed AAV vectors encoding $\mathrm{hCB}_{2}(\mathrm{D} 80 \mathrm{~N})$ (Fig. 2).

\section{Construction of AAV Vectors Encoding $\mathrm{hCB}_{\mathbf{2}}(\mathrm{D} 80 \mathrm{~N})$}

Two AAV vectors (AAV2/7) containing $\mathrm{hCB}_{2}(\mathrm{D} 80 \mathrm{~N})$ were generated. Bicistronic AAV constructs encoding $\mathrm{hCB}_{2}(\mathrm{D} 80 \mathrm{~N})$ with either eGFP or fLuc were made (Fig. 2 ), driven by the hCMVie promoter. The open reading frames of each protein were separated by a viral self-cleaving 2A-like peptide sequence, namely T2A of the Thosea asigna insect virus, which allows equimolar expression of both proteins $(2,22)$.

To evaluate the transduction efficiency of the AAV vectors, a Wistar rat was injected stereotactically with $5 \mu \mathrm{L}$ of AAV-eGFP-T2A-hCB 2 (D80N) $(\mathrm{E}+11 \mathrm{GC} / \mathrm{mL})$ in the RS and $5 \mu \mathrm{L}$ of AAV-eGFP-T2A-fLuc $(\mathrm{E}+12 \mathrm{GC} / \mathrm{mL})$ in the contralateral striatum. The animal was sacrificed 1 wk later and brain $\mathrm{CB}_{2}$, eGFP, and CD68 (activated microglia or macrophages) were detected in brain sections using immunohistochemistry (Fig. 3A-3D). $\mathrm{CB}_{2}$ and eGFP were coexpressed in the right hemisphere (Fig. 3D). No overlay was seen between the $\mathrm{CB}_{2}{ }^{+}$and $\mathrm{CD} 68^{+}$cells.

To assess long-term in vivo small-animal PET, 2 rats were injected under the same conditions and scanned 6,13 , 18 , and $96 \mathrm{~d}$ after surgery. Immunohistochemistry was performed on 1 animal after scanning on day 18. Smallanimal PET images were analyzed and binding potential calculated (Fig. 4C). The time-activity curve of ${ }^{11} \mathrm{C}$ GW405833 in 1 rat $18 \mathrm{~d}$ after stereotactic injection is shown in Figure 3G. Average uptake in the RS (AAVeGFP-T2A-hCB $2(\mathrm{D} 80 \mathrm{~N})$ ) was 1.8 times higher than uptake in the LS (AAV-eGFP-T2A-fLuc), also demonstrated in a summed image of 30-60 min after injection (Fig. 3E).

After in vivo validation of the $\mathrm{hCB}_{2}(\mathrm{D} 80 \mathrm{~N}) \mathrm{AAV}-$ based reporter gene system, specific binding of ${ }^{11} \mathrm{C}-\mathrm{GW} 405833$ was confirmed by a chase study $41 \mathrm{~d}$ after vector injection. Nonradioactive GW405833 (5 mg/kg) was administered approximately $20 \mathrm{~min}$ after tracer injection (Fig. 3G). The activity level in the RS dropped to the level in the contralateral hemisphere, demonstrating competition-induced tracer dissociation (Figs. 3F and 3G). Afterward, the animal was sacrificed, and immunohistochemistry confirmed coexpression of $\mathrm{CB}_{2}$ and eGFP in the right hemisphere (data not shown).

Next, AAV-fLuc-T2A-hCB 2 (D80N) was produced to allow dual-mode imaging (Fig. 2). Rats were injected with

FIGURE 3. Small-animal PET of AAVmediated $\mathrm{hCB}_{2}(\mathrm{D} 80 \mathrm{~N})$ reporter gene expression in rat brain. (A-D) Triple fluorescent immunohistochemistry of RS of Wistar rat 1 wk after stereotactic injection of $5 \mathrm{E}+08 \mathrm{GC}$ AAV-eGFP-T2A-hCB ${ }_{2}(\mathrm{D} 80 \mathrm{~N})$. Control vector AAV-eGFP-T2A-fLuc (5E+09 GC) was injected in contralateral hemisphere. (A-C) Staining for eGFP (fluorescein isothiocyanate) (A), $\mathrm{CD}^{+} 8^{+}$-activated microglia and macrophages (Alexa $555 \mathrm{~nm}$ ) (B), $\mathrm{CB}_{2}$ (647 $\mathrm{nm})(\mathrm{C})$, and overlay image (D). Colocalization of both eGFP and $\mathrm{CB}_{2}$ was observed in RS. (E) Summed small-animal PET image of 30-60 min after injection of ${ }^{11} \mathrm{C}-\mathrm{GW} 405833$ at $18 \mathrm{~d}$ after stereotactic injection of $5 \mu \mathrm{L}$ of AAV-eGFP-T2A-hCB ${ }_{2}$ (D80N) $(5 E+08 \mathrm{GC})$ in RS and $5 \mu \mathrm{L}$ of AAV-eGFP-T2A-fLuc $(5 E+09 \mathrm{GC})$ in the $\mathrm{LS}$ in rat. $(F)$ Summed small-animal PET image of 30-90 min after injection of ${ }^{11} \mathrm{C}$-GW405833 at $41 \mathrm{~d}$ after surgery, whereby nonradioactive GW405833 (5 mg/kg, arrow) was administered $20 \mathrm{~min}$ after tracer injection. As a result, no significant ${ }^{11} \mathrm{C}-\mathrm{GW} 405833$ tracer binding was detected. (G) Corresponding time-activity curves of ${ }^{11} \mathrm{C}$-GW405833 at 18 and $41 \mathrm{~d}$
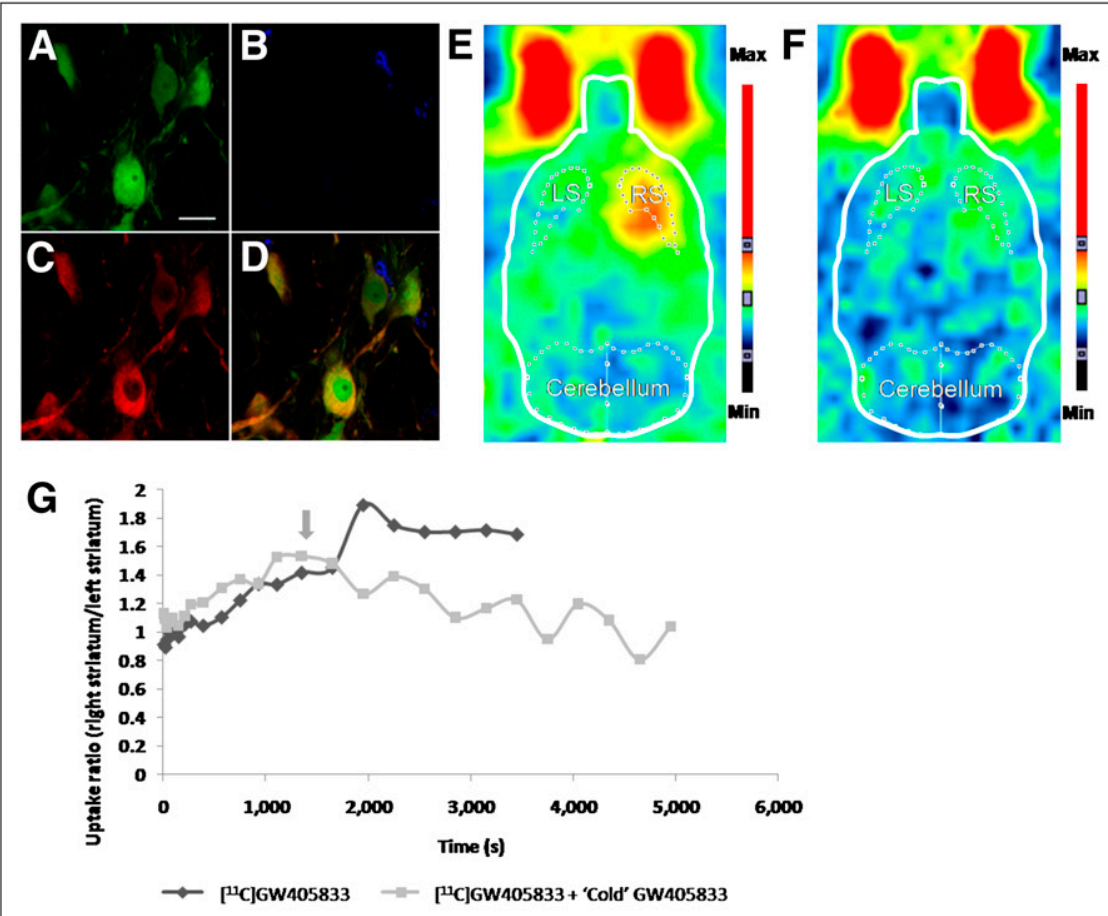
after surgery in same animal. After administration of nonradioactive GW405833 (5 mg/kg, arrow), activity in RS dropped to activity level in LS, indicating competition of tracer binding and confirming specific binding of ${ }^{11} \mathrm{C}-\mathrm{GW} 405833$. Scale bar $=20 \mu \mathrm{m}$. Max $=$ maximum; $\min =\operatorname{minimum}$. 


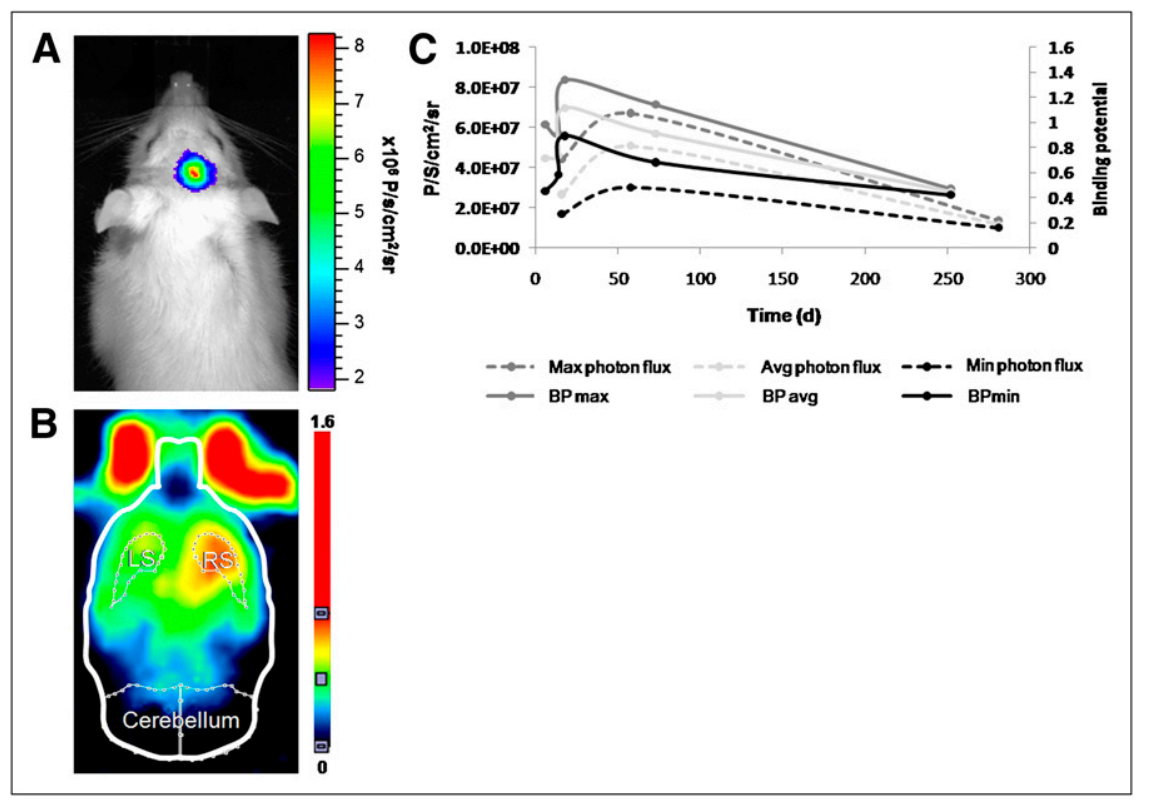

FIGURE 4. Bimodal BLI/small-animal PET of AAV-transduced brain cells. BLI and small-animal PET of rats stereotactically injected with $5 \mu \mathrm{L}$ of AAV-fLuc-T2A$\mathrm{hCB}_{2}(\mathrm{D} 80 \mathrm{~N})(5 \mathrm{E}+08 \mathrm{GC})$ in RS. (A) Representative photon flux $58 \mathrm{~d}$ after stereotactic surgery. (B) Binding potential image of representative animal $73 \mathrm{~d}$ after surgery. (C) Follow-up over time of binding potential of ${ }^{11} \mathrm{C}-\mathrm{GW} 405833$ at 14,73 , and $252 \mathrm{~d}$ after surgery or photon flux at 16,58 , and $281 \mathrm{~d}$ after surgery. BLI signal at $281 \mathrm{~d}$ corresponds to average of $1,952 \mathrm{CB}^{+}$cells detected by immunohistochemistry (range, 727-3,067). avg = average; $\mathrm{BP}=$ binding potential; $\max =$ maximum; $\min =$ minimum.
$5 \mu \mathrm{L}$ of AAV-fLuc-T2A-hCB $2(\mathrm{D} 80 \mathrm{~N})(\mathrm{E}+11 \mathrm{GC} / \mathrm{mL})$ in the RS and followed over time with bioluminescence imaging (BLI) $(n=3)$ and ${ }^{11} \mathrm{C}-\mathrm{GW} 405833$ small-animal PET $(n=5)$. BLI scans were obtained at 16,58 , and $281 \mathrm{~d}$ and small-animal PET scans at 14, 73, and $252 \mathrm{~d}$ after surgery. Figure 4A shows the photon flux of a rat injected with luciferin at $58 \mathrm{~d}$ after stereotactic injection of the vector. Figure 4B shows a representative slice of a binding potential image at $73 \mathrm{~d}$ after surgery of an animal. Both $\mathrm{hCB}_{2}(\mathrm{D} 80 \mathrm{~N})$ expression and fLuc activity are detected in the RS.

Figure 4C shows the follow-up by ${ }^{11} \mathrm{C}-\mathrm{GW} 405833$ smallanimal PET and BLI until 252 and $281 \mathrm{~d}$ after surgery, respectively. PET binding potential and BLI photon flux followed a similar course. The observed signal initially increased over time and reached a maximum in the RS between 18 and $58 \mathrm{~d}$ after vector injection in the brain. Afterward, the animals were perfused, and immunohistochemical analysis for $\mathrm{CB}_{2}$ was performed (mean $\mathrm{CB}_{2}{ }^{+}$ cells in the right hemisphere, 1,952 [range, 727-3,067]).

\section{DISCUSSION}

Reporter genes are essential in the evaluation and followup of gene therapy applications. Nonimaging markers such as $\beta$-galactosidase and eGFP can be detected on immunohistochemical staining but require tissue sampling by way of biopsy or necroscopy (3). Secreted transgenes such as secreted placental alkaline phosphatase or factor IX can be measured over time by body fluid sampling but fail to provide details about localization of gene expression (23). Noninvasive imaging can facilitate monitoring of gene expression over time, thereby reducing cohort size and inherent measurement variability. The radiotracer approach has sufficient sensitivity to quantitatively measure gene expression in vivo and is translationally applicable for use in humans $(24,25)$. The aim of this study was to develop a new PET reporter gene system and validate it for brain applications (26). As shown in this study, $\mathrm{hCB}_{2}(\mathrm{D} 80 \mathrm{~N})$ fulfils many of the criteria of an ideal reporter gene system (7), especially specificity for $\mathrm{hCB}_{2}(\mathrm{D} 80 \mathrm{~N})$ and rapid crossing of the intact BBB.

In view of the high lipophilicity of ${ }^{11} \mathrm{C}-\mathrm{GW} 405833$, predominant hepatobiliary excretion can be expected. In rats, the gastrointestinal tract showed some initial activity, which decreased as a function of time while activity in the liver gradually increased. This gradual increase might be explained by enterohepatic circulation with intestinal resorption of excreted ${ }^{11} \mathrm{C}-\mathrm{GW} 405833$ or its metabolites and subsequent accumulation in the liver. Enterohepatic circulation also explains the stable blood concentration between 10 and $30 \mathrm{~min}$ after injection observed in both mice and rats (Table 1 and Supplemental Table 1). Binding to $\mathrm{CB}_{2^{-}}$ expressing leukocytes is less likely responsible for slow blood clearance, because we did not observe $\mathrm{CB}_{2}$ binding in the spleen.

${ }^{11} \mathrm{C}-\mathrm{GW} 405833$ showed rapid metabolism, with only $15 \%$ intact tracer left in plasma at $30 \mathrm{~min}$ after injection in mice. Despite the stable plasma activity concentrations, a fast clearance of the fraction of intact tracer was observed as shown by the rapid metabolism. Ideally, radiometabolites should be absent in the brain to allow accurate quantification of receptor binding with PET. At $10 \mathrm{~min}$ after injection, only $10 \%$ of the observed brain activity was present as radiometabolites.

Successful PET ligands for the central nervous system have generally high affinity for their receptor and are moderately lipophilic, as high nonspecific binding and low brain penetration are usually observed with very lipophilic compounds. The favorable characteristics for BBB passage (low molecular weight, $1<\log \mathrm{D}<3$, PSA $<9 \mathrm{~nm}^{2}[90$ 
$\AA^{2}$ ]) of ${ }^{11} \mathrm{C}-\mathrm{GW} 405833$ are confirmed by the biodistribution data showing high brain uptake of ${ }^{11} \mathrm{C}-\mathrm{GW} 405833$ (Table 1), also confirming the results from Valenzano et al., who described high brain uptake of GW405833 in rats (17). The small-animal PET study in the primate model confirmed the high brain uptake of ${ }^{11} \mathrm{C}-\mathrm{GW} 405833$, but the brain washout was slower than observed in rats.

Unlike $\mathrm{CB}_{1}$, there is low endogenous expression of $\mathrm{CB}_{2}$ in the healthy mammalian brain, although $\mathrm{CB}_{2}$ can be upregulated in inflammatory conditions (27). To quantify possible confounding signal due to procedure-induced inflammation, control vector injections were performed in the contralateral hemisphere. The spleen has the highest population of $\mathrm{CB}_{2}$, and therefore tracer accumulation in the spleen or a slower washout from spleen was anticipated. However, we did not observe specific binding in the spleen for ${ }^{11} \mathrm{C}-\mathrm{GW} 405833$. Possibly, the affinity of the tracer is insufficient to visualize the limited endogenous receptor expression. A maximal binding capacity $\left(\mathrm{B}_{\max }\right)$ value of $0.71 \mathrm{pmol} / \mathrm{mg}$ for rat spleen and $0.31 \mathrm{pmol} / \mathrm{mg}$ for mouse spleen has been described using the nonspecific agonist ${ }^{3} \mathrm{H}-$ CP55,940 (28). As a general rule, to be able to visualize a receptor, the affinity value $\left(\mathrm{K}_{\mathrm{d}}\right)$ should be 5-10 times smaller than the $B_{\max }\left(B_{\max } / K_{d}>5-10\right)$. Thus, to be able to visualize endogenous $\mathrm{CB}_{2}$ in the spleen, a radioligand with subnanomolar affinity $(0.03-0.1 \mathrm{nM})$ would be required. Background signal could be a possible problem on translation of this reporter system to a primate or human context. When tested in the primate model, also in areas with known discrete $\mathrm{CB}_{2}$ expression, such as the pons and cerebellum, the probe showed no measurable background signal. The question remains to what extent upregulation of the $\mathrm{CB}_{2}$ receptor in activated microglia during acute or chronic inflammation increases background signal and thus potentially would interfere with this reporter system.

GW405833 was described by Valenzano et al. as a partial agonist on $\mathrm{CB}_{2}$ with high affinity for $\mathrm{hCB}_{2}\left(\mathrm{~K}_{\mathrm{i}} \mathrm{hCB}_{2} R=\right.$ $3.9 \mathrm{nM}$ ) (17). In our assay, GW405833 shows a 10 -fold lower affinity for $\mathrm{hCB}_{2}$ and behaved as an inverse agonist in our GTP $\gamma \mathrm{S}$ assay. Our results are in accordance with those of Yao et al., who reported that GW405833 is a potent inverse agonist in both $\mathrm{hCB}_{2}\left(\mathrm{EC}_{50}, 44.4 \mathrm{nM}\right)$ and $\mathrm{rCB}_{2}$ $\left(\mathrm{EC}_{50}, 3.3 \mathrm{nM}\right)$ (29). Recently, Mancini et al. defined GW405833 as a protean agonist (30). We report a 200 -fold selectivity versus $\mathrm{hCB}_{1}$ which is lower than the selectivity reported by Valenzano et al. (1,200-fold), but higher than that reported by Yao et al. (37-fold) and comparable to that observed by Gallant et al. (160-fold) $(16,29,30)$.

Similar to an existing dopamine receptor $\left(\mathrm{D}_{2} \mathrm{R}\right)$ gene reporter system, for which the reporter probes (e.g., ${ }^{18} \mathrm{~F}$ 3 -( $2^{\prime}-{ }^{18} \mathrm{~F}$-fluoroethyl)-spiperone) are able to cross the BBB (31) but suffer from high background signal in $\mathrm{D}_{2} \mathrm{R}$-rich brain regions, a mutation has been applied in a highly preserved aspartic acid residue in the second transmembrane domain of $\mathrm{hCB}_{2}(\mathrm{D} 80 \mathrm{~N})$, providing a disconnection of ligand binding from signal transduction $(13,32)$. In consequence, endo- or exogenous ligands have little or no effect on the signal transduction pathway that is activated after normal endogenous $\mathrm{CB}_{2}$ binding. Binding itself is probably not hampered, because experimental and computational modeling studies indicate that interactions with residues of helices 3-7 account for most of the known ligand- $\mathrm{CB}_{2}$ interactions (33).

When using viral vectors, an important asset is the size of the reporter gene. With a size of about $1 \mathrm{~kb}, \mathrm{hCB}_{2}(\mathrm{D} 80 \mathrm{~N})$ fits in both lentiviral and AAV vector transfer plasmids, allowing coexpression with other imaging reporter genes such as fLuc and eGFP or even with (future) therapeutic genes (22). In theory, the $\mathrm{hCB}_{2}(\mathrm{D} 80 \mathrm{~N})$ lentiviral constructs can be used for stem cell tracking in the brain or other stem cell applications, although the sensitivity of the system still needs to be determined. $\mathrm{hCB}_{2}(\mathrm{D} 80 \mathrm{~N})$-expressing AAV constructs were added to our platform of $\mathrm{CB}_{2}$ constructs to ensure high in vivo transduction efficiency after injection in the brain. Interestingly, we detected a decrease in AAVmediated transgene expression in both imaging modalities over a period of about $9 \mathrm{mo}$, possibly due to promoter silencing, loss of epigenetic vector genomes, or an immune response. Nevertheless, this modest decrease does not significantly hamper the potential use of long-term gene reporter monitoring with this system.

\section{CONCLUSION}

A new PET reporter gene system was developed showing good $\mathrm{BBB}$ penetration and reversible and specific $\mathrm{CB}_{2}$ binding in vivo. Imaging of $\mathrm{CB}_{2}$ expression depends on several factors, such as the level of $\mathrm{CB}_{2}$ expression in the transduced tissue and the affinity, selectivity of the $\mathrm{CB}_{2}$ radioligand, and system sensitivity. Application of the system for gene expression has been further investigated in preclinical models and in alternative applications such as stem cell tracking.

\section{DISCLOSURE STATEMENT}

The costs of publication of this article were defrayed in part by the payment of page charges. Therefore, and solely to indicate this fact, this article is hereby marked "advertisement" in accordance with 18 USC section 1734.

\section{ACKNOWLEDGMENTS}

We thank Peter Vermaelen and Ann Van Santvoort for their skillful help with the small-animal PET scans and Evy Lobbestael for her help with confocal microscopy. We are also grateful to Veerle Reumers and Sylvie De Swaef for their help with the histologic analysis. We gratefully acknowledge the staff of radiopharmacy of UZ Leuven for their help with the radiopharmaceutical preparations. This study is supported by the European Commission for EC-FP6-STREP-STROKEMAP, BRAINSTIM SBOIWT-060838, DIMI LSHB-CT-2005-512146, and the K. U. Leuven Center of Excellence "MoSAIC." No other 
potential conflict of interest relevant to this article was reported.

\section{REFERENCES}

1. Manfredsson FP, Mandel RJ. Development of gene therapy for neurological disorders. Discov Med. 2010;9:204-211.

2. Szymczak AL, Vignali DA. Development of $2 \mathrm{~A}$ peptide-based strategies in the design of multicistronic vectors. Expert Opin Biol Ther. 2005;5:627-638.

3. Spergel DJ, Kruth U, Shimshek DR, Sprengel R, Seeburg PH. Using reporter genes to label selected neuronal populations in transgenic mice for gene promoter, anatomical, and physiological studies. Prog Neurobiol. 2001;63:673-686.

4. Chalfie M, Tu Y, Euskirchen G, Ward WW, Prasher DC. Green fluorescent protein as a marker for gene expression. Science. 1994;263:802-805.

5. Contag CH, Spilman SD, Contag PR, et al. Visualizing gene expression in living mammals using a bioluminescent reporter. Photochem Photobiol. 1997;66:523-531.

6. Gambhir SS, Bauer E, Black ME, et al. A mutant herpes simplex virus type 1 thymidine kinase reporter gene shows improved sensitivity for imaging reporter gene expression with positron emission tomography. Proc Natl Acad Sci USA. 2000;97:2785-2790.

7. Gambhir SS, Herschman HR, Cherry SR, et al. Imaging transgene expression with radionuclide imaging technologies. Neoplasia. 2000;2:118-138.

8. Cho SY, Ravasi L, Szajek LP, et al. Evaluation of (76)Br-FBAU as a PET reporter probe for HSV1-tk gene expression imaging using mouse models of human glioma. J Nucl Med. 2005;46:1923-1930.

9. Hirvonen J, Aalto S, Lumme V, et al. Measurement of striatal and thalamic dopamine D2 receptor binding with ${ }^{11} \mathrm{C}$-raclopride. Nucl Med Commun. 2003; 24:1207-1214.

10. Kogan NM, Mechoulam R. Cannabinoids in health and disease. Dialogues Clin Neurosci. 2007;9:413-430.

11. Roth MD, Baldwin GC, Tashkin DP. Effects of delta-9-tetrahydrocannabinol on human immune function and host defense. Chem Phys Lipids. 2002;121:229239.

12. Maresz K, Carrier EJ, Ponomarev ED, Hillard CJ, Dittel BN. Modulation of the cannabinoid $\mathrm{CB} 2$ receptor in microglial cells in response to inflammatory stimuli. J Neurochem. 2005;95:437-445.

13. Tao Q, Abood ME. Mutation of a highly conserved aspartate residue in the second transmembrane domain of the cannabinoid receptors, CB1 and CB2, disrupts G-protein coupling. J Pharmacol Exp Ther. 1998;285:651-658.

14. Evens N, Bormans GM. Non-Invasive Imaging of the Type 2 Cannabinoid Receptor, Focus on Positron Emission Tomography. Curr Top Med Chem. 2010;10:1527-1543.

15. Horti AG, Gao Y, Ravert HT, et al. Synthesis and biodistribution of $\left[{ }^{11} \mathrm{C}\right] \mathrm{A}-$ 836339, a new potential radioligand for PET imaging of cannabinoid type 2 receptors (CB2). Bioorg Med Chem. 2010;18:5202-5207.

16. Gallant M, Dufresne C, Gareau Y, et al. New class of potent ligands for the human peripheral cannabinoid receptor. Bioorg Med Chem Lett. 1996;6:2263-2268.

17. Valenzano KJ, Tafesse L, Lee G, et al. Pharmacological and pharmacokinetic characterization of the cannabinoid receptor 2 agonist, GW405833, utilizing rodent models of acute and chronic pain, anxiety, ataxia and catalepsy. Neuropharmacology. 2005;48:658-672.

18. Chitneni SK, Serdons K, Evens N, et al. Efficient purification and metabolite analysis of radiotracers using high-performance liquid chromatography and online solid-phase extraction. J Chromatogr A. 2008;1189:323-331.

19. Muccioli GG, Wouters J, Charlier C, et al. Synthesis and activity of 1,3,5triphenylimidazolidine-2,4-diones and 1,3,5-triphenyl-2-thioxoimidazolidin-4ones: characterization of new CB1 cannabinoid receptor inverse agonists/antagonists. J Med Chem. 2006;49:872-882.

20. Casteels C, Vermaelen P, Nuyts J, et al. Construction and evaluation of multitracer small-animal PET probabilistic atlases for voxel-based functional mapping of the rat brain. J Nucl Med. 2006;47:1858-1866.

21. Filppula S, Yaddanapudi S, Mercier R, Xu W, Pavlopoulos S, Makriyannis A. Purification and mass spectroscopic analysis of human CB2 cannabinoid receptor expressed in the baculovirus system. J Pept Res. 2004;64:225-236.

22. Ibrahimi A, Vande Velde G, Reumers V, et al. Highly efficient multicistronic lentiviral vectors with peptide 2A sequences. Hum Gene Ther. 2009;20:845-860.

23. Wooddell CI, Reppen T, Wolff JA, Herweijer H. Sustained liver-specific transgene expression from the albumin promoter in mice following hydrodynamic plasmid DNA delivery. J Gene Med. 2008;10:551-563.

24. Penuelas I, Mazzolini G, Boan JF, et al. Positron emission tomography imaging of adenoviral-mediated transgene expression in liver cancer patients. Gastroenterology. 2005;128:1787-1795.

25. Yaghoubi SS, Jensen MC, Satyamurthy N, et al. Noninvasive detection of therapeutic cytolytic T cells with ${ }^{18} \mathrm{~F}$-FHBG PET in a patient with glioma. Nat Clin Pract Oncol. 2009;6:53-58.

26. Bjorklund T, Kordower JH. Gene therapy for Parkinson's disease. Mov Disord. 2010;25 (suppl 1):S161-S173.

27. Cabral GA, Raborn ES, Griffin L, Dennis J, Marciano-Cabral F. CB2 receptors in the brain: role in central immune function. Br J Pharmacol. 2008;153:240-251.

28. Govaerts SJ, Hermans E, Lambert DM. Comparison of cannabinoid ligands affinities and efficacies in murine tissues and in transfected cells expressing human recombinant cannabinoid receptors. Eur J Pharm Sci. 2004;23:233-243.

29. Yao BB, Hsieh GC, Frost JM, et al. In vitro and in vivo characterization of A-796260: a selective cannabinoid CB2 receptor agonist exhibiting analgesic activity in rodent pain models. Br J Pharmacol. 2008;153:390-401.

30. Mancini I, Brusa R, Quadrato G, et al. Constitutive activity of cannabinoid-2 (CB2) receptors plays an essential role in the protean agonism of (+)AM1241 and L768242. Br J Pharmacol. 2009;158:382-391.

31. MacLaren DC, Gambhir SS, Satyamurthy N, et al. Repetitive, non-invasive imaging of the dopamine D2 receptor as a reporter gene in living animals. Gene Ther. 1999;6:785-791.

32. Liang Q, Satyamurthy N, Barrio JR, et al. Noninvasive, quantitative imaging in living animals of a mutant dopamine D2 receptor reporter gene in which ligand binding is uncoupled from signal transduction. Gene Ther. 2001;8:1490-1498.

33. Diaz P, Phatak SS, Xu J, et al. 2,3-Dihydro-1-benzofuran derivatives as a series of potent selective cannabinoid receptor 2 agonists: design, synthesis, and binding mode prediction through ligand-steered modeling. ChemMedChem. 2009; $4: 1615-1629$. 